\title{
COMPARISONS OF DESIGN METHODS OF SHEAR CAPACITY AND FLEXURAL CAPACITY USING FIBER REINFORCED POLYMER IN CONCRETE BEAM
}

\author{
Anand Erdenebileg ${ }^{1}$ \\ ${ }^{1}$ School of Civil Engineering, Lanzhou Jiaotong University, Lanzhou 730070, PR China
}

\begin{abstract}
In the last two decades, civil engineering and construction industry have been using innovative technologies. One of these technologies is the Fiber Reinforced Polymers. The topic has been studied by many researchers and professional organizations around the world to enhance the application of the FRP in the industry. However, in order to use as the substitute of traditional materials such as steel, making higher performance, longer lasting, higher strength, extending life are still questionable, also the calculation methods with current building codes are in need to inform the audience. In my thesis, flexural and shear design of the concrete beams using Fiber Reinforced Polymers is discussed. This work compares the flexural design methods according to the American Concrete Institute (ACI) and Chinese CECS 146-2003 guidelines, and shear design methods according to the American Concrete Institute (ACI) and Canadian ISIS code (ISIS-M03-07). Also the research discusses the types and FRP composites' properties that are available, and examines methods to calculate typical reinforced concrete beams. To highlight analytical and theoretical design guidelines on the shear contribution as well as the flexural contribution of the Fiber Reinforced Polymer to Reinforced Concrete beams.
\end{abstract}

Keywords: Shear Capacity, Flexural Capacity, Fiber Reinforced Polymer, Concrete Beam

\section{INTRODUCTION}

Fiber-reinforced polymer is a composite material made of a polymer matrix reinforced with fibers. The fibers are usually glass, carbon, or aramid, although other fibers such as paper or wood or asbestos have been sometimes used. The polymer is usually an epoxy, vinyl ester or polyester thermosetting plastic, and phenol for1maldehyde resins are still in use. FRPs are commonly used in the aerospace, automotive, marine, and construction industries. (Zhi, 2007)The polymer reinforcement bars have differences from typical steel reinforcement bars and they depend on fiber types, matrixes, volume fraction etc.

Hurricanes, tornadoes, tsunamis, earthquakes and other disasters could destroy structures in a second. Not only disasters, saltwater, deicing chemicals, and freeze-thaw cycles also can cause the structural deterioration. The buildings that were built many years ago were built according to older building codes; these buildings could be harmed and destroyed more by extreme events, and these need to be retrofitted with current building codes. Concrete and steel jacketing are some of the retrofit technique, however using them increases the cross sectional area of the column, and the methods seem to take time and needs more labors in order to complete. So far, the best method for retrofitting for a repair has been Fiber Reinforced Polymers.(Azadeh Parvin, 2014)

The fiber reinforced polymer composites (FRPs) are increasingly used and playing important role on the constructions and infrastructures than traditional civil engineering materials, namely concrete and steel. FRP composites have many advantages, name a few: FPR are lightweight, no-corrosive, can have high specific strength and specific stiffness, easier to construct, and be able to modify to satisfy the purpose. Due to these advantageous characteristics, FRP composites are being included in new construction and rehabilitation of structures through its use as reinforcement in concrete, bridge decks, modular structures, formwork, and external reinforcement for strengthening and seismic upgrade.(Masuelli, 2013)

Fiber-Reinforced Polymer are made from two or more constituent materials with significantly different physical or chemical properties which remain separate and distinct within the finished structure. The composites have strong, stiff fibers in a matrix which could result as weaker and less stiff. Glass or carbon fibers are found in matrixes of commercial materials (epoxy or polyester resins). Thermoplastic polymers are moldable right after producing, thus thermoplastic polymers are more used. Metal and ceramic matrix composite is present; however these are still being developed and researched. Adding fibers could be time consuming and complex, such as fracture toughness, thermal stability, wear are still being questioned. (Masuelli, 2013)

The fibers of FRP composites serve as main load carrying member and resin matrix serve as protection of fiber and load transferring. According to many experimental and analytical studies, their results said that more than $59.3 \%$ load carrying capacity is acquired after using FRP as shear strength. On column, FRP is used in order to increase ductility and axial load carrying capacity. (Rai., 2015) 


\section{CALCULATION METHODS}

\subsection{Flexural Capacity Calculation Method of FRP} on Concrete Beam

\subsubsection{ACI Code}

With beams reinforced with FRP longitudinal reinforcement, the contribution of concrete to shear strength tends to be reduced because of the smaller concrete compression zones, wider cracks and smaller dowel forces. When concrete beam has FRP stirrups, shear failure happens when FRP ruptures at bent points or by shear-compression failure in the shear span.(Davalos; \& Triantafillou, 2002)

Stress concentration's failure could limit the effective capacity as little as $35 \%$ of the strength.(Shehata, 2000)The failure modes using ACI Code was also included the shear failure due to FRP rupture, shear failure without FRP rupture, shear failure due to FRP de-bonding and due to mechanical anchors. (Teng, 2003)

According to the American Concrete Institute (ACI-440, 2001) the flexural capacity depends if the structure is controlled by concrete crushing or FRP rupture. Computing FRP reinforcement ratio and balanced ratio and comparing the results, the failure mode can be decided (when the concrete crushing and FRP rupture happen at the same time). With the usage of design tensile strength, FRP reinforcement balanced ratio is computed because the FRP has no capability to yield.

FRP reinforcement ratio:

$\rho_{f}=\frac{A_{f}}{b d}$

FRP balanced reinforcement ratio:

$\rho_{f b}=0.85 \beta_{1} \frac{f_{c}^{\prime}}{f_{f u}} \frac{E_{f} \varepsilon_{c u}}{E_{f} \varepsilon_{c u}+f_{f u}}$

(ACI-440, 2001)

If $\rho_{f}<\rho_{f b}$, FRP rupture governs, and the under reinforced section will fail in tension. Before the failure, FRP reinforcement will not yield; therefore when the bar ruptures, concrete crushes. In the end the moment capacity of the section cannot be calculated. However, (ACI-440, 2006) advised to use the following equation to calculate the nominal flexural capacity.
$M_{n}=A_{f} f_{f u}\left(d-\frac{\beta_{1} c_{b}}{2}\right)$

$c_{b}=\left(\frac{\varepsilon_{c u}}{\varepsilon_{c u}+\varepsilon_{f u}}\right) d c_{b}-$ depth of neutral axis at balanced

reinforcement ratio

In order to keep for not failing at concrete cracking, a minimum amount of flexural reinforcement should be calculated:

$$
A_{f, \min }=\frac{4.9 \sqrt{f^{\prime}}}{f_{f u}} b d \geq \frac{330}{f_{f u}} b d
$$

If $\rho_{f}>\rho_{f b}$, concrete crushing governs, over-reinforced section fails because of the concrete crushing. The nominal moment capacity is calculated similar to that for a section for which reinforced with steel reinforcement:

$$
M_{n}=A_{f} f_{f}\left(d-\frac{a}{2}\right)
$$

$a=\frac{A_{f} f_{f}}{0.85 f^{\prime}{ }_{c} b}$

$$
f_{f}=\left(\sqrt{\frac{\left(E_{f} \varepsilon_{c u}\right)^{2}}{4}+\frac{0.85 \beta_{1} f_{c}^{\prime}}{\rho_{f}} E_{f} \varepsilon_{c u}}-0.5 E_{f} \varepsilon_{c u}\right)
$$

where $f_{f}$ - stress in the FRP rebar at compressive failure; $a-$ depth of stress block .(Bank, 2008)

Fire rating of the strengthened reinforced concrete can be increased by using the insulation system, because the insulation system can postpone the durability of steel and concrete. If the FRP temperatures are below a critical temperature, the contribution of the FRP system should be considered.

In order to prevent the de-bonding in regions away from FRP termination, the following equation is used.

$$
\varepsilon_{f d}=0.41 \sqrt{\frac{f^{\prime} c}{n E_{f} t_{f}}} \leq 0.9 \varepsilon_{f u}
$$


$\varepsilon_{f e}=\varepsilon_{c u}\left(\frac{h-c}{c}\right)-\varepsilon_{b i} \leq 0.9 \varepsilon_{f d}$

To estimate the neutral axis, it is assumed that the neutral axis is $20 \%$ of the effective section depth.

\section{cest $\approx 0.20 d$}

The determination of the effective level of strain in the reinforcement is given below

$$
\mathcal{E}_{f e}=\boldsymbol{\varepsilon}_{c u}\left(\frac{d_{f}-c}{c}\right)-\boldsymbol{\varepsilon}_{b i} \leq 0.9 \mathcal{E}_{f d}
$$

The flexural strain has to be based on failure mode. Each material's (concrete, steel etc) flexural strain needs to be calculated.

$$
\mathcal{E}_{s}=\left(\mathcal{E}_{f e}-\mathcal{E}_{b i}\right)\left(\frac{d-c}{d_{f}-c}\right)
$$

Calculation of steel and FRP stress

Steel stress: $f_{s}=E_{s} \mathcal{E}_{s} \leq f_{y}$

FRP stress: $f_{f e}=E_{s} \varepsilon_{f e}$

Intern al force resultants are calculated by following equations

$$
\begin{aligned}
& \varepsilon^{\prime}{ }_{c}=\frac{1.7 f^{\prime} c}{E e} \\
& \beta_{1}=\frac{4 \varepsilon^{\prime} c-\varepsilon c}{6 \varepsilon^{\prime} c-2 \varepsilon c} \\
& \alpha_{1}=\frac{4 \varepsilon^{\prime} c \varepsilon c-\varepsilon c^{2}}{3 \beta 1 \varepsilon^{\prime} c^{2}}
\end{aligned}
$$

The force equilibrium is checked

$$
c=\frac{A_{s} f_{s}+A_{f} f_{f e}}{\alpha 1 f_{c}^{\prime} \beta 1 b}
$$

Finally, the design flexural strength is computed:

$$
\phi M_{n}=\phi\left[A_{s} f_{s}\left(d-\frac{\beta 1 c}{2}\right)+\psi A_{f} f_{f e}\left(h-\frac{\beta 1 c}{2}\right)\right]
$$

where $\psi=0.85$ (for FRP)

$$
\phi M n>M u(\text { Witt, 2008) }
$$

\subsubsection{CECS-146 Guidelinesof the PR China}

ECS 146-2003 is considered as the first guideline in China for the design, construction and quality control of concrete structures that were reinforced with carbon fiber reinforced polymer (CFRP) laminate. It was titled "technical specification for strengthening concrete structures with carbon fiber reinforced polymer laminate (CECS-146: 2003)." Using CECS 146-2003, the cubic strength of concrete $f_{c u}$ has to be less than 50MPa. There are 6 assumptions that can carry out the flexural capacity design:

1. Panes remain plain

2. Perfect bond exists between FRP laminate and the bottom of the concrete beam until flexural failure

3. Stress vs. strain relationship has to be elastoplastic

4. Tensile strength of concrete is ignored

5. FRP laminate behaves linearly elastic until tension failure

6. The unidirectional stress-strain for compressive concrete is suggested as follows:

$$
\begin{aligned}
& \sigma_{c}=\sigma_{0}\left[1-\left(1-\frac{\varepsilon_{c}}{\varepsilon_{0}}\right)^{2}\right] \\
& \left(\varepsilon_{c} \leq \varepsilon_{c}\right) \\
& \sigma_{c}=\sigma_{0} \\
& \left(\varepsilon_{0}<\varepsilon_{c} \leq \varepsilon_{c u}\right)
\end{aligned}
$$

$\sigma_{c} \varepsilon_{c}-$ stress and strain of compressive concrete

$\sigma_{0}-$ compressive strength of concrete

$\varepsilon_{0}$ - peak strain of concrete corresponding to $\sigma_{0}$

$\varepsilon_{c u}-$ ultimate compressive strain $\varepsilon_{c u}=0.0033$ 

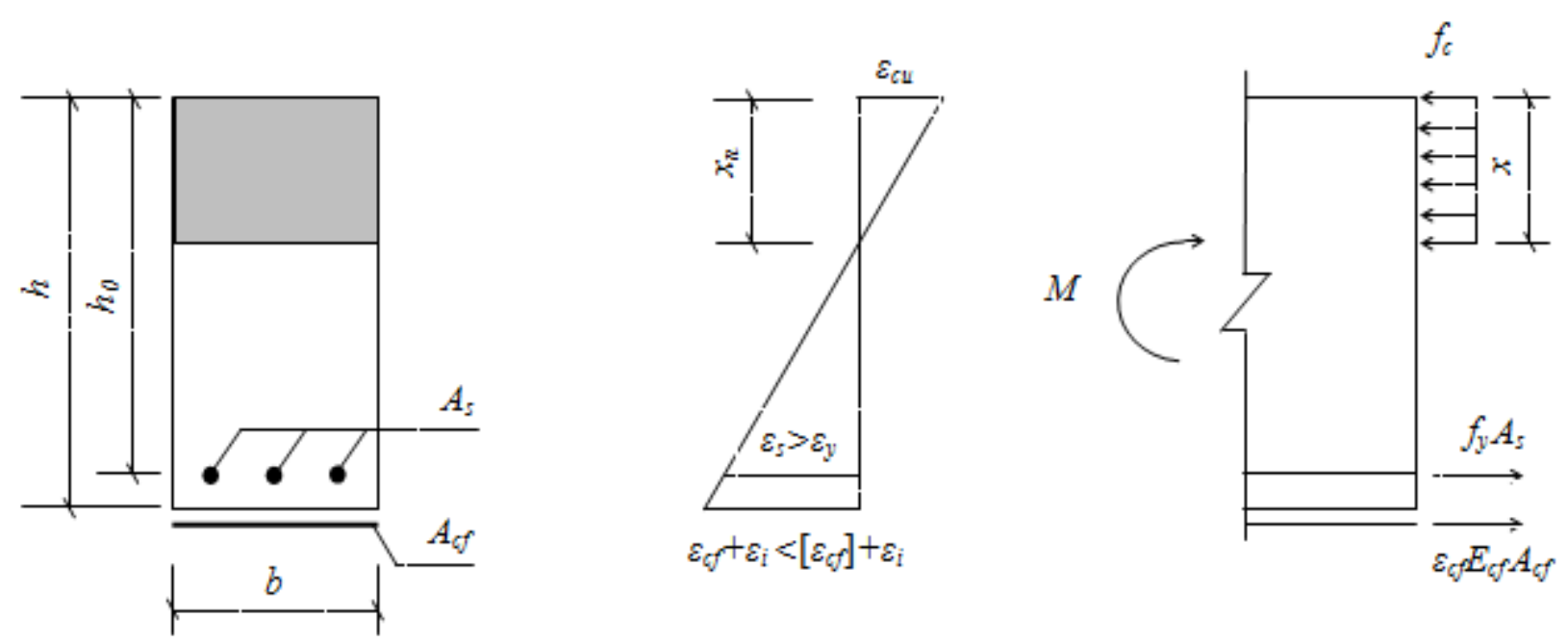

(a) $\xi_{c j} h<x<\xi_{b} h_{0}$
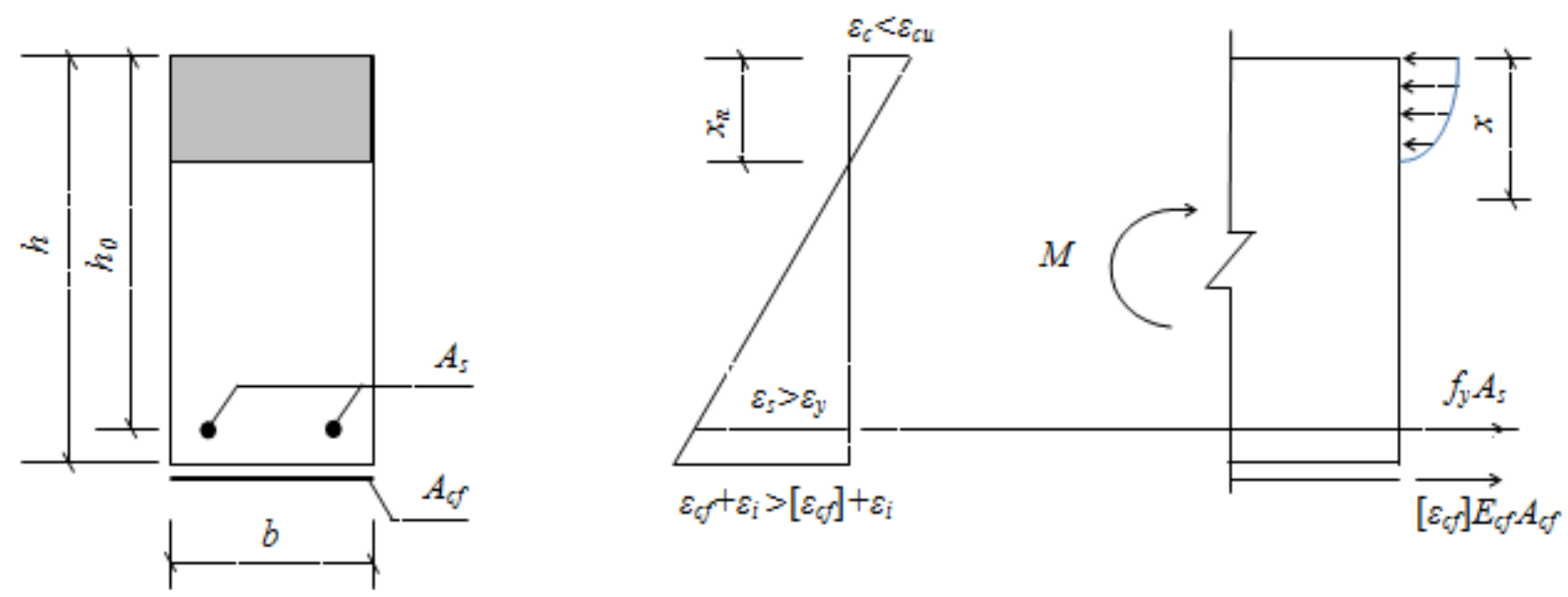

(b) $x<\xi_{c f s} h$


(c) $x>\xi_{b} h_{0}$

(a) First failure (b) Second failure (c) Third failure

Fig 1 shows the distribution of the stress and strain distributions. 
To identify the failure modes, CECS146 Code introduced two parameters $\xi_{b}$ and $\xi_{c f b}$.

$\xi_{b}$ is the boundary relative depth of the rectangular stress block, $x / h_{0}$, when the steel yields and when the concrete crushes $\left(\varepsilon_{c u}=0.0033\right) . h_{0}$ is the effective depth.

$\xi_{c f b}$ is explained as the boundary relative depth of the rectangular stress block, when FRP laminate reaches its allowable tensile strain $\varepsilon_{c f}=\left[\varepsilon_{c f}\right]$ and when the concrete crushes $\left(\varepsilon_{c u}=0.0033\right)$.

$\xi_{b}=\frac{\beta_{1}}{1+f_{y} / \varepsilon_{c u} E_{s}}$

$\xi_{c f b}=\frac{\beta_{1} \varepsilon_{c u}}{\varepsilon_{c u}+\left[\varepsilon_{c f}\right]+\varepsilon_{i}}$

Where:

$f_{y}$ - factored steel yield strength of steel,

Es - Modulus of Elasticity of steel,

$\beta_{1}-$ stress block factor for concrete

$\beta_{1}=x / x_{n}$

(when $f_{c u}<50 \mathrm{MPa}, \beta_{1}=0.8$ )

$x_{n}$ - depth of concrete compressive zone

The allowable tensile strain $\left[\varepsilon_{c f}\right]$ for FRP laminate is calculated as the product of thickness reduction factor $\left[k_{m}\right]$ and ultimate tensile strain of FRP $\left[\varepsilon_{c f u}\right]$.

The allowable tensile $\left[\varepsilon_{c f}\right]$ should not be greater than $2 / 3 \varepsilon_{c f u}$ or 0.01 .

The thickness reduction factor:

$k_{m}=\frac{1-n_{c f} E_{c f} t_{c f}}{420000}$

where $n_{c f}$ - number of layers of FRP laminates; $t_{c f}$ - thickness of FRP laminates;

$E_{c f}$ - Modulus of Elastic of FRP laminates.

The ultimate tensile strain $\left[\varepsilon_{c f u}\right]$ for FRP is calculated by the following:

$$
\varepsilon_{c f u}=\frac{f_{c f k}}{E_{c f k}} \text { where }_{c f k}-\text { specified tensile strength of FPR }
$$

laminates

\section{First Failure Mode}

When $\xi_{c f b} h<x<\xi_{c f b} h_{0}$, the first failure mode would occur. Therefore the sectional flexural capacity is computed as:

$$
M=f_{c} b x\left(h_{0}-0.5 x\right)+E_{c f} \varepsilon_{c f} A_{c f}\left(h-h_{0}\right)
$$

where $f_{c}$ - factored compressive cylinder strength of concrete $b$ - width; $h$ - height; $A_{c f}$ - sectional area of FRP laminate bonded to bottom surface of concrete beam; $\varepsilon_{c f}-$ strain of FRP laminate.

$$
\begin{aligned}
& f_{c} b x=f_{y} A_{s}+E_{c f} \varepsilon_{c f} A_{c f} \\
& x=\frac{\beta_{1} \varepsilon_{c u}}{\varepsilon_{c u}+\varepsilon_{c f}+\varepsilon_{i}} h
\end{aligned}
$$

where $\varepsilon_{i}-$ initial bottom strain by initial moment acting upon concrete beam

\section{Second Failure Mode}

If $x<\xi_{c f b} h$, the second failure occurs; FRP laminate reaches or exceeds after steel yields, the resultant of compressive concrete is equal to $E_{c f}\left[\varepsilon_{c f}\right] A_{c f}+f_{y} A_{s}$.

The flexural capacity is calculated as:

$$
M=E_{c f}\left[\varepsilon_{c f}\right] A_{c f} h\left(1-0.5 \xi_{c f b}\right)+f_{y} A_{s}\left(h_{0}-0.5 \xi_{c f b} h\right)
$$

\section{Third Failure Mode}

If $x>\xi_{c f b} h$, the last failure mode occurs, and the flexural capacity is calculates as:

$$
M=E_{s} \varepsilon_{s} A_{s}\left(h_{0}-0.5 x\right)+E_{c f} \varepsilon_{c f} A_{c f}(h-0.5 x)
$$

(Zheng He, 2007)

CECS guideline applies when the cubic strength of concrete $f_{c u}$ should not be more than 50MPa.There are 3 failure modes that could occur with the above assumptions:

1. After steel's yielding, the concrete crushes, FPR does not reach its allowable tensile strain $\varepsilon_{c f}$

2. FPR laminates reaches or out passes allowable tensile strain after steel's yielding, and the concrete does not crush

3. Due to over-strengthening, concrete crushes before steel's yielding(Zheng He, 2007)

FRP-strengthened beams are governed by the equation below:

$$
\gamma_{0} S_{d} \leq R_{d}
$$

\footnotetext{
$S_{d^{-}}$factored load effect

$R_{d^{-}}$factored resistance

$\gamma_{0}$-importance factor $\left(\gamma_{0}=1.0\right.$ for reliability assessment) (GB50068-2001, 2001)
} 
Dead load effect and floor live load effect can be the main factors when designing the flexural capacity design. $S_{d}$ in the above equation is computed as:

$$
\begin{aligned}
& S_{d}=\gamma_{G 1} S_{G k}+\gamma_{Q} S_{Q k} \\
& S_{d}=\gamma_{G 2} S_{G k}+\gamma_{Q} \psi_{c} S_{Q k}
\end{aligned}
$$

The maximum $S_{q}$ is taken

$S_{G k}, S_{q k}-$ load effects caused by dead and live load

$\gamma_{G 1} \gamma_{G 2}$ - partial safety factor of dead load $\left(\gamma_{G 1}=1.2, \gamma_{G 2}=1.35\right)$

$\gamma_{Q^{-}}$partial safety factor of live load $\left(\gamma_{Q}=1.4\right)$

$$
\psi_{c} \text { - combination factor }\left(\psi_{c}=0.7\right)
$$

The factored compressive cylinder strength of concrete $\left(f_{c}\right)$ and the factored yielding strength of steel $\left(f_{y}\right)$ ought to be calculated:

$$
\begin{aligned}
& f_{c}=f_{c k} / \gamma_{c} \\
& f_{y}=f_{y k} / \gamma_{s}
\end{aligned}
$$

$f_{c k}-$ specified compressive cylinder strength partial safety factor of concrete $\left(\gamma_{c}=1.40\right)$ $f_{y k}$ - specified yielding strength of steer partial safety factor of steel $\left(\gamma_{s}=1.10\right)$

(GB50009-2001, 2006)

\subsection{Shear Capacity Calculation Method of FRP on}

\section{Concrete Beam}

\subsubsection{ACI 318 Code}

Many researches on the FRP reinforced concrete beams tell us that the shear capacity of the concrete beams with longitudinal and transverse FRP reinforcement can be validated when employing the classical methods; these methods are carried out designing structures, such as beams, reinforced with conventional reinforcement. (Juozas Valivonis, 2015)

Designing concrete structure with FRP reinforcement is very identical to steel reinforced concrete structure. However, because FRP reinforcement's mechanical properties are not same as its counterparts, it could affect the shear resistance. From ACI 318-05,

$$
V_{n}=V_{c}+V_{s}+V_{f}
$$

Where $V c$ is concrete shear capacity, $V s$ is transverse steel shear capacity. From its steel reinforcement counterpart, the FRP reinforcement cracking depth is smaller because the axial stiffness is much lower. $\left(E_{s} \mathrm{x} A\right)$ The crack widths are wider and the compression region tends to be reduced, so the shear resistance is smaller. The member with FRP reinforcement concrete shear capacity is calculated by:
$V_{c}=5 \sqrt{f_{c}} b_{w} c$

Where $b_{w}-$ Width of the web $c$ - cracked transformed section neutral axis depth

For singly reinforced, rectangular cross sections, theneutral axis depth $c$ may be computed as

$c=k d$

$k=\sqrt{2 \rho_{f} n_{f}+\left(\rho_{f} n_{f}\right)^{2}}-\rho_{f} n_{f}$

$\rho_{f}=\frac{A_{f}}{b_{w} d}$

Where

$\rho_{f}-$ FRP Reinforcement Ratio

$n_{f}-$ Modular ratio

(ACI-440, 2006)

$V_{s}$ and $V_{c}$ are based on the current design codes, meaning steel stirrups crossed by shear cracks are estimated to reach yield strength at beam shear failure. (J.F.Chen, 2010)

The design approach based on the effective FRP stress is identical to the approach for designing steel shear reinforcement. At ultimate, the stress in the vertical direction ought to be measured, multiplied by the area (shear crack). The rupture point, instead of yield point must be recognized. From stress concentrations in the sheet, the FPR sheets were at stress level below ultimate strength. At rupture, when the level of strain is the effective strain, the shear capacity of a reinforced concrete beam was created by Triantafillou. (Ahmed Khalifa, 1998)

$$
V_{f}=\rho_{f} E_{f} \varepsilon_{f e} b_{w} 0.9 d(1+\cot \beta) \sin \beta
$$

(Triantafillou, 1998)

$\rho_{f}-$ FRP shear reinforcement ratio

$\beta-$ angle between orientation of fibers in the sheet and longitudinal axis

The equation is written in ACI code format as:

$V_{f}=\frac{A_{f} f_{f e}(\sin \beta+\cos \beta) d f}{S f}$

Note: if continuous strips are used, the width of the strip $w_{f}$ and the spacing of the strip $s_{f}$ are equal. (Ahmed Khalifa, 1998)

For transverse steel shear capacity $V_{s}$, The ACI Code has given us the equation: 
$V_{s}=\frac{A f f_{y v} d f}{S f}$

Where:

$A_{v}$ - Total cross-sectional area of the steel reinforcement

$f_{y v}-$ Yielding strength

$s_{f}$ - spacing of transverse reinforcement (K.Galal, 2004)

The nominal shear strength of the concrete is computed as follows:

$$
\phi V_{n}=0.85\left(V_{s}+V_{c}\right)+0.7 V f
$$

\subsubsection{Shear Capacity Calculation Method of FRP on Concrete Beam using ISIS-M03-07}

In this section, we will examine the shear capacity method on concrete beams for the Canadian Standard Association design manual ISIS-M03-07 Code. Comparing with steel reinforcement, FRP reinforcement bars have different mechanical properties; they tend to have linear elastic behavior with brittle fracture, also the elastic modulus is lower than the steel reinforcement. The FRP bars have lower strength in the transverse direction as opposed to the strengths in the longitudinal directions. Lower Modulus of Elasticity $E$ can impact transverse steel shear capacity and concrete shear capacity. (Ahmed K. El-Sayad, 2011)

The concrete shear can be influenced by the contributions from un-cracked concrete, aggregate interlock, dower action, and residual stresses across the inclined cracks. Because of the low Modulus of Elasticity, wider and deeper cracks are at sight in the concrete members reinforced with longitudinal FRP bars. According to El-Sayad and Soudki [2011], deeper cracks decrease the contribution to shear strength from the un-cracked concrete due to lower depth of concrete in compression. Also wider cracks decrease the contributions from aggregate interlock and residual tensile stresses.

In order to make anchorage, stirrups are bent. The studies showed that bent part of FRP is less than that of straight part. At the bend, reduced strength helps stress concentration to be stable and helps fibers to be stable perpendicular to the axis. Bending process, the radius of the bend $r_{b}$, reinforcing fiber types, bar diameters $d_{b}$ are major components that influence the bend capacity of the FRP bars. [ACI] The stirrup capacity $V_{s}$ is depended on bend strength of FRP stirrups on the strain limits. (Ahmed K. El-Sayad, 2011)

The design equation from the Japan Society of Civil Engineers for FRP with bent portions is as follows:

$$
f_{f b}=\left(0.05 \frac{r_{b}}{d_{b}}+0.3\right) f_{f w}
$$

\section{ISIS-M03-07 Design Manual}

For members with effective depth lower than $300 \mathrm{~mm}$, the shear capacity of concrete is as follows:

$V_{c}=0.2 \lambda \phi_{c} \sqrt{f^{\prime}{ }_{c}} b_{w} d \sqrt{\frac{E_{f l}}{E_{s}}}$ (ISIS-Canada-Research-

Network, 2007)

For members with effective depth greater than $300 \mathrm{~mm}$, the shear capacity of concrete is as follows:

$V_{c}=\left(\frac{260}{1,000+d}\right) \lambda \phi_{c} \sqrt{f^{\prime}{ }_{c}} b_{w} d \sqrt{\frac{E_{f l}}{E_{s}}} \geq 0.1 \lambda \phi_{c} \sqrt{f^{\prime}{ }_{c}} b_{w} d \sqrt{\frac{E_{f l}}{E_{s}}}$

The transverse steel shear capacity is as follows:

$V_{s}=\frac{\phi_{f} A_{f v} f_{f_{v}} d_{v} \cot \theta}{s}$

$d_{v}=0.9 d \quad$ - effective shear depth

$\theta \quad$ - Inclination angle of shear plane

ISIS manual does not provide how to calculate the angle $\theta$.

The stress level in the FRP shear reinforcement is calculated as:

$f_{f v}=\frac{\left(0.05 \frac{r_{b}}{d_{b}}+0.3\right) f_{u v}}{1.5}$

Or

$f_{f v}=E_{f v} \varepsilon_{f v}$
$\varepsilon_{f v}=0.0001 \sqrt{f^{\prime}{ }^{\prime}{ }^{\frac{\rho_{f l} E_{f l}}{\rho_{f v} E_{f v}}}\left[1+2\left(\frac{\sigma_{n}}{f^{\prime}{ }_{c}}\right)\right] \leq 0.0025}$

Where $\rho_{f v}=$ shear reinforcement ratio; $E_{f v}=$ modulus of elasticity of the shear reinforcement; and $\sigma_{\mathrm{n}}=$ stress in concrete due to axial load.

(Ahmed K. El-Sayad, 2011) 


\subsection{Comparisons}

\subsubsection{Comparison of Flexural Calculations using}

\section{ACI and CECS Codes}

\section{CECS 146-2003 Code}

According to the Chinese CECS 146-2003 Code, the Code is valid and usable if the cubic strength of concrete is not more than 50MPa, rather in ACI there is no assumption. The Code has included two parameters in order to identify the failure modes. CECS Code, comparing with ACI, is considered as conservative. Depending on the failure mode, which the code mentioned three failure mode, the flexural capacity is calculated.

\section{ACI Code}

The flexural capacity of a concrete member reinforced with FRP reinforcement is decided similar to the steel reinforcement. The ultimate strength of FRP reinforcement bars succeeds the yield strength of steel bars in the concrete beam design formula (only if the plane sections remain same, and the bars are bonded to concrete perfectly) since FRP reinforcement bars do not yield.

The ACI Code for computing flexural capacity of the concrete member reinforced with FRP is considered as a conservative when the FRP rupture governs. (Failure in tension) Because the FRP reinforcement does not yield and when the bar ruptures, the concrete crushes. ACI recommends when designing the section capacity, suitable non-linear stress-strain relations of concrete is strongly advised.

When the concrete member's over-reinforced section fails during the concrete crushing, the nominal moment is calculated as similar to that of the concrete structure reinforced with steel.

\subsubsection{Comparison of Shear Calculations using ACI and ISIS Codes}

\section{ACI Code}

ACI Code recognizes the following failure modes:

-Shear failure due to FRP rupture

-Shear failure without FRP rupture

-Shear failure due to FRP de-bonding

-Mechanical anchors

The failure modes using ACI Code was also included the shear failure due to FRP rupture, shear failure without FRP rupture, shear failure due to FRP de-bonding and due to mechanical anchors. (Teng, 2003)

ACI recognizes the shear strength the sum of maximum contribution to all material types, e.g. concrete, FRP, stirrups. According to (Monti, 2014), ACI overestimates the shear strength of reinforced concrete strengthened with FRP.
The shear capacity of concrete members with FRP reinforcement loaded in flexure is impacted by the mechanical properties of main tension FRP reinforcement bars as well as FRP shear reinforcement. Lower modulus of FRP reinforcement main bars make shallower compression zone and increases the deflection at flexure when compared to steel reinforcement main bars. (Bank, 2008)

\section{ISIS Code}

From the other literature (Ahmed K. El-Sayad, 2011) the author completed the shear experiments based on the shear design provisions, and 149 beams and slabs were tested examining its shear data and validity of various codes. According to the test results, FRP reinforced concrete beams provisioned by the ISIS code was to be very conservative for shear strength of the specimen.

When the FRP stirrups are used, there are three concerns:

1. FRP stirrup bent's tension capacity

2. Tail length requirement for FRP stirrups

3. FRP stirrup minimum radius of bent

From ISIS, it is assumed that when the tensile capacity of stirrups is reached, or when the web concrete crushes the shear failure occurs. The code suggests assigning a total limit on the total shear resistance of the member. (ISISCanada-Research-Network, 2007)

\section{CONCLUSION}

This paper has compared the calculation methods and design guidelines of flexural capacity of the FRP reinforced concrete beam using the American Concrete Institute (ACI 440) and Chinese CECS-146 guidelines, as well as shear capacity of the FRP reinforced concrete beam using the American Concrete Institute (ACI 440) and the Canadian ISIS-M03-07 guidelines.

\section{ACI 440 and CECS 146}

Comparing the ACI 440 and CECS-146 design codes, the Chinese code is more conservative and the failure mode for CECS is obtained by additional two parameters, where ACI does not have. CECS Code has three failure modes depending on the calculation of two new parameters $\xi_{b}$ and $\xi_{c f b}$.

In ACI 440, to find the failure modes, the reinforced ratio is compared to the balanced reinforced ratio of FRP reinforcement. If the reinforced ratio is less than the balanced reinforced ratio the FRP rupture governs the failure of concrete structure; if the reinforced ratio is more than the balanced ratio the concrete structure is failed because of concrete crushing.

\section{ACI 318 and ISIS-M03-07}

Both ACI and ISIS codes assume that the cracks are deeper and wider, which make the shear strength smaller. However, ISIS Code calculates shear capacity of concrete based on the effective depth, while the ACI Code does not specify whether the shear capacity of concrete depends on the amount of effective depth. 


\section{NOTATIONS}

The following symbols are used in this paper:

$a$ Depth of the equivalent rectangular concrete stress block

$A_{s} \quad$ Area of tension steel

$A_{f}\left(A_{c f}\right) \quad$ Area of FRP reinforcement

$A_{f v}$ nominal cross-sectional area of FRP

stirrups within a spacing $s$

$b\left(b_{w}\right) \quad$ Width of concrete

$c_{\text {est }} \quad$ Depth of the neutral axis

$c \quad$ Force equilibrium

$d\left(d_{f}\right) \quad$ Effective section depth

$c_{b} \quad$ Depth of neutral axis

$E_{s} \quad$ Modulus of Elasticity of steel

$E_{c} \quad$ Modulus of Elasticity of concrete

$E_{c f} \quad$ Modulus of Elasticity of FRP laminates

$E_{f v} \quad$ Modulus of Elasticity of shear

reinforcement Existing state of strain

$\varepsilon_{c u} \quad$ Maximum compressive strain

$\varepsilon_{c f} \quad$ Allowable tensile strain of FRP

$\varepsilon_{c f u} \quad$ Ultimate tensile strain of FRP

$\varepsilon_{f e} \quad$ Effective level of strain

$\varepsilon_{i} \quad$ Initial bottom strain

$\varepsilon_{s} \quad$ Steel strain

$\varepsilon_{c} \quad$ Concrete strain

$\varepsilon_{0} \quad$ Peak strain of concrete corresponding to

$f_{f e}\left(f_{f v}\right) \quad$ Stress level in FRP

$f_{f} \quad$ Stress in rebar at compressive failure

$f_{f u} \quad$ Ultimate tensile strength

$f_{f v} \quad$ Design stress of FRP stirrup

$f_{s} \quad$ Steel stress

$f_{c f k} \quad$ tensile strength of FRP laminates

$f_{c} \quad$ Factored compressive cylinder strength of

concrete

$f_{c}^{\prime} \quad$ Concrete compressive strength

$f_{y}\left(f_{y v)} \quad\right.$ Steel yield stress

$f_{\text {fe }} \quad$ FRP stress

$h \quad$ height of the concrete beam

$M_{n}(M) \quad$ design flexural strength

$\sigma_{c} \quad$ Concrete compressive stress

$\sigma_{0} \quad$ Compressive strength of concrete

$\sigma_{n} \quad$ Stress in concrete due to axial loading

$\xi_{b} \quad$ Boundary relative depth

$\xi_{c f b} \quad$ Boundary relative depth when FRP reaches its

allowable tensile strain $\varepsilon_{c f}=\left[\varepsilon_{c f}\right]$ and when concrete crushes

$\beta_{1} \quad$ Stress block factor for concrete

$x_{n} \quad$ Depth of concrete compressive zone

$k_{m} \quad$ Thickness reduction factor

$n_{c f} \quad$ Numbers of layers of FRP laminates

$s_{f} \quad$ spacing of transverse reinforcement

$t_{c f} \quad$ Thickness of FRP laminates

$V_{c} \quad$ Concrete shear capacity

$V_{f} \quad$ FRP laminate shear capacity

$V_{s} \quad$ Steel shear capacity

$c \quad$ Cracked transformed section neutral axis

$\rho_{f}\left(\rho_{f v}\right) \quad$ FRP reinforcement ratio

$n_{f} \quad$ Modular ratio $\beta$ sheet and longitudinal axis

$\lambda$ factor accounting for concrete density

$\phi_{c} \quad$ Resistance factor for concrete

$\phi_{f} \quad$ Resistance factor for FRP

$\phi_{s} \quad$ Resistance factor for steel

$\theta \quad$ Inclination angle of shear plane

\section{REFERENCES}

[1] ACI-440. (2001). Guide for the Design and Construction of Concrete Reinforced with FRP Bars (ACI 40.1R-01) (pp. 41). Farmington Hills, MI, USA: American Concrete Institute.

[2] ACI-440. (2006). Guide for the Design and Construction of Structural Concrete Reinforced with FRP Bars ACI 440.1R-06 (pp. 44): American Concrete Institute.

[3] Ahmed K. El-Sayad, K. S. (2011). Evaluation of Shear Design Equations of Concrete Beams with FRP Reinforcement. [Academic]. JOURNAL OF COMPOSITES FOR CONSTRUCTION, 15(1), 9-20. doi: 10.1061/ASCECC.1943-5614.0000158

[4] Ahmed Khalifa, A. N. a. M. I. A. A. (1998). Contribution of Externally Bonded FRP to Shear Capacity of RC Flexural Members. ASCE-Journal of Composites for Construction,, 2(4), 195-203. doi: 10.1061/(ASCE)1090-0268(1998)2:4(195)

[5] Azadeh Parvin, D. B. (2014). FRP Composites Strengthening of Concrete Columns under Various Loading Conditions. Polymers, 6, 17. doi: 10.3390/polym6041040

[6] Bank, L. C. (2008). Design of FRP Reinforced and Strengthened Concrete. In E. G. Nawy (Ed.), Concrete Construction Engineering Handbook (Vol. 1, pp. 1-22): CRC Press.

[7] Davalos;, C. E. B. L. C. B. V. L. B. E. C. J. F., \& Triantafillou, J. J. L. A. M. S. H. R. a. T. C. (2002). Fiber-Reinforced Polymer Composites for Construction - State-of-the-Art Review. JOURNAL OF COMPOSITES FOR CONSTRUCTION, 73-87. doi: 10.1061/(ASCE)1090-0268(2002)6:2(73)

[8] GB50009-2001. (2006). Load Code for the Design of Building Structures (2nd Edition in Chinese). Beijing, China: China Architecture \& Building Press.

[9] GB50068-2001. (2001). Unified Standard for Reliability Design of Building Structures (2nd edition In Chinese). Beijing, China: China Architecture \& Building Press.

[10] ISIS-Canada-Research-Network. (2007). Reinforcing Concrete Structures with Fiber Reinforced Polymer Design Manual No. 3, Version 2 (3 ed.). Winnipeg, Manitoba, Canada: ISIS Canada Research Network.

[11] J.F.Chen, G. M. C. J. G. T. (2010). RC beams shearstrengthened with FRP: shear resistance contributed by FRP. Magazine of Concrete Research,, 62(4), 301-311. doi: 10.1680/macr.2010.62.4.301

[12] Juozas Valivonis, M. B., Mantas Atutis,Edgaras Atutis and Linas Juknevic ius. (2015). Study on shear resistance of fiber reinforced polymer-reinforced 
concrete beams. Advances in Mechanical Engineering, 7(7), 1-7. doi: 10.1177/1687814015593873

[13] K.Galal, A. G. (2004). SHEAR CAPACITY OF RETROFITTED RECTANGULAR RC SHORT COLUMNS. 13th World Conference on Earthquake Engineering, Paper No. 1495.

[14] Masuelli, M. A. (2013). Fiber Reinforced Polymers The Technology Applied for Concrete Repair: InTech.

[15] Monti, F. P. G. (2014). FRP-RC Beam in Shear: Mechanical Model and AssessmentProcedure for Pseudo-Ductile Behavior Polymers, 6, 2051-2064. doi: 10.3390/polym6072051

[16] Rai., D. C. L. C. H. C. G. L. (2015). STRENGTHENING OF RCC STRUCTURES USING FRP COMPOSITE TECHNOLOGY. IJRET: International Journal of Research in Engineering and Technology, 4(13).

[17] Shehata, E., Morphy, R., and Rizkalla, S. (2000). FiberReinforced Polymer Composites for ConstructionState-of-the-Art Review. Can. J. Civ. Eng., 27(5), 859872.

[18] Teng, J. F. C. a. J. G. (2003). Shear Capacity of FiberReinforced Polymer-Strengthened

[19] Reinforced Concrete Beams: Fiber Reinforced Polymer Rupture. JOURNAL OF STRUCTURAL ENGINEERING, 129(5), 615-625. doi: 10.1061/(ASCE)0733-9445(2003)129:5(615)

[20] Triantafillou, T. C. (1998). Shear Strengthening of Reinforced Concrete Beams Using Epoxy-Bonded FRP Composites. ACI Structural Journal.

[21] Witt, S. (2008). The Design of Fiber Reinforced Polymers for Structural StrengtheningAn Overview of ACI 440 Guidelines. PPT Presentation. Fyfe Company.

[22] Zheng He, L. J. (2007). Flexural Reliability Assessment of FPR-Strengthened Reinforced Concrete Designed by Chinese CECS-146 Guideline. Pacific Science Review, 9(1), 123-133.

[23] Zhi, W. (2007). The development and application of composite materials Retrieved June 19 2016, from http://www.yourpaper.net/article/20071124/66959.html 